\title{
Effect of amino acid infusion on perioperative thermoregulation in newborn surgery
}

\author{
Mustafa Okumuş ${ }^{1} \odot$, Faik Tansu Salman²๑
}

${ }^{1}$ Department of Pediatric Surgery, Yeni Yüzyll University School of Medicine, Gaziosmanpaşa Hospital, İstanbul, Turkey

${ }^{2}$ Department of Pediatric Surgery, İstanbul University, İstanbul School of Medicine, İstanbul, Turkey

\begin{abstract}
Objectives: Decreased drug metabolism, coagulation disorders, wound infections, and cardiac arrhythmias are the most important and well-known results of intraoperative hypothermia. Perioperative amino acid infusion is known to prevent intraoperative hypothermia during general anesthesia in adults. In this study, we aimed to demonstrate the effect of perioperative amino acid infusion on the prevention of hypothermia during general anesthesia in newborn surgery.
\end{abstract}

Methods: Twenty surgical newborns, aged 1-30 days, were enrolled in this prospective randomized controlled study. Newborns were assigned randomly into two groups: the amino acid/dextrose (AAD) group and the dextrose (D) group. The core temperatures of the newborns were measured from the distal esophagus in the first minute of the induction once and every fifteen minutes thereafter. The core body temperature changes in each group during the operation and the differences between the two groups were analyzed.

Results: The surgical operations in each group were similar. The mean operating room temperatures of AAD and $\mathrm{D}$ groups were $25.4 \pm 0.2^{\circ} \mathrm{C}$ and $25.3 \pm 0.3^{\circ} \mathrm{C}$, respectively. There were no significant differences in the general characteristics of the two groups. The mean core temperatures began to decrease after the induction of anesthesia in both groups and continued to decrease during the course of the surgery. There was no significant difference between the two groups.

Conclusions: Hypothermia develops in all neonates when surgical time exceeds one hour, even in warmer ambient temperatures. Although it seems effective in adults, amino acid-induced thermoregulation does not seem effective in newborns during general anesthesia.

Keywords: Amino-acid, anesthesia, hypothermia, newborn, thermoregulation

D ecreased metabolic rate and impaired thermoregulation during general anesthesia cause significant undesirable effects, even in adults [1,2]. Newborns, having a larger surface area and less subcutaneous fatty tissue covering central structures, are more susceptible to these inadvertent effects. Decreased drug metabolism, coagulation disorders, wound infections, and cardiac arrhythmias are the most important and well-known results [3, 4].

Core body temperature has to be kept at a constant level $\left(37^{\circ} \mathrm{C}\right)$ in each environment for the continuation of metabolic functions [2]. Peripheral arteriovenous shunts, sweating, shivering, and non-shivering heat generation constitute important intervention mechanisms in conscious individuals [3]. General anesthesia and surgery are frequently accompanied by hypother- 
mia related to the impairment of thermoregulation and synchronous reduction of vasoconstriction thresholds and shivering [1]. Body heat is redistributed from the core to the periphery shortly after induction of anesthesia and results in a decrease in core temperature. The course is followed by heat loss exceeding metabolic heat production.

Patients can be intensively warmed or simply kept warm either by elevating the ambient temperature or by the use of extracorporeal devices such as forced-air warming blowers and infusion fluid warming devices during general anesthesia [3, 5]. As a different approach, perioperative amino acid infusion is known to prevent intraoperative hypothermia during general anesthesia in adults [6-11].

Due to the high amount of brown adipose tissue, non-shivering thermogenesis is used in preference to shivering in newborns[1, 12-14]. Despite all compensatory mechanisms, newborns have a limited capacity for thermoregulation and are prone to hypothermia. Although there are several studies about amino acidinduced thermoregulation in adults, there is no study in newborns and infants related to the subject. In this study, we aimed to demonstrate the effect of perioperative amino acid infusion on the prevention of hypothermia during general anesthesia in surgical newborns.

\section{METHODS}

The study protocols were reviewed and approved by the ethics committee of İstanbul University, İstanbul School of Medicine. All parents were informed about the study before giving their consent to participate. Twenty surgical newborns, aged 1-30 days, were enrolled in this prospective, randomized controlled study. Newborns with fever, sepsis, and those undergoing surgical procedures shorter than 60 min were not included in the study.

Newborns were randomly divided into two groups: the amino acid and dextrose $10 \%$ infusion group (AAD) and the $10 \%$ dextrose only infusion group (D). Amino acid (TrophAmine ${ }^{\circledR} 6 \%$, B. Braun Hessen, Germany) solution was given at a rate of $1 \mathrm{~g} / \mathrm{kg}-124 \mathrm{~h}-1$ and dextrose $10 \%$ solution was given at a rate $100 \mathrm{~mL} \mathrm{~kg}-124 \mathrm{~h}-1$ before and during the operation.
No premedication was given before surgery. The ambient operating room temperature was maintained near $25^{\circ} \mathrm{C}$. All newborns received general anesthesia with sevoflurane and air O2.Tracheal intubation was facilitated with rocuronium. Ventilation was controlled and adjusted to keep end-tidal $\mathrm{CO} 2$ at 4.6-5.2 $\mathrm{kPa}$ (35-40 mm Hg). All newborns were placed on warm gel pads, which were placed on a constant electrical heating pad that was adjusted to $37^{\circ} \mathrm{C}$ (KanMedOperatherm 202; KanMed AB, Bromma, Sweden). A heat and moistureexchanger was connected to the tracheal tube connector in all newborns. The head, legs, and arms were covered by warm cotton.

The age, sex, weight, hemoglobin concentration, primary pathology, preoperative infusion time, duration of anesthesia, the initial core temperature of the newborns, and the ambient operating room temperature were recorded. The core temperatures of the newborns were measured from the distal esophagus in the first minute of the induction once and every fifteen minutes thereafter. Thermocouple probes (Ellab YRYT, Ellab, Hillerod, Denmark) were connected to the Mennen Horizon XL monitor (Mennen Medical Ltd., Rehovot, Israel).

\section{Statistical Analysis}

The core body temperature changes in each group during surgery and the differences between the two groups were analyzed. Statistical analysis was performed using the SPSS 11 package program. Descriptive data are expressed as mean \pm standard deviation and number (\%). Continuous variables are given as mean \pm standard deviation and categorical variables as percentage (\%). Independent group comparisons were made using Student's t-test when parametric test assumptions were provided. The Mann-Whitney U test was used when parametric test assumptions were not provided. The Chi-square test was used to determine categorical variables. $P$ values $<0.05$ were considered statistically significant.

\section{RESULTS}

A total of 20 surgical newborns were enrolled in the study. The diagnoses of the newborns are shown in Table 1. The surgical operations in each group were 


\section{Table 1. Diagnosis of the patients}

\begin{tabular}{cc}
\hline $\begin{array}{c}\text { Dextrose } \\
\text { (D) group }\end{array}$ & $\begin{array}{c}\text { Amino acid and dextrose } \\
\text { (AAD) group }\end{array}$ \\
\hline $\begin{array}{c}\text { Midgut volvulus } \\
\text { Congenital diaphragmatic } \\
\text { hernia }\end{array}$ & $\begin{array}{c}\text { Gastric perforation } \\
\text { Pyloric atresia }\end{array}$ \\
$\begin{array}{c}\text { Congenital diaphragmatic } \\
\text { hernia }\end{array}$ & Duodenal atresia \\
Duodenal atresia & Midgut volvulus \\
Malrotation & $\begin{array}{c}\text { Volvulus and internal } \\
\text { hernia }\end{array}$ \\
Pyloric stenosis & Gastric perforation \\
Pyloric stenosis & Ileal atresia \\
\hline $\begin{array}{c}\text { Necrotizing enterocolitis } \\
\text { Congenital diaphragmatic } \\
\text { hernia }\end{array}$ \\
Malrotation & Meconium ileus \\
\hline $\begin{array}{c}\text { Intraabdominal cystic } \\
\text { mass }\end{array}$ & Pyloric stenosis \\
\hline
\end{tabular}

similar. Operating room temperatures were constant within the limit of $\pm 0.5^{\circ} \mathrm{C}$ for each group during the course of surgery. The mean operating room temperatures of the AAD and $\mathrm{D}$ groups were $25.4 \pm 0.2^{\circ} \mathrm{C}$ and $25.3 \pm 0.3^{\circ} \mathrm{C}$, respectively.

Table 2 illustrates the perioperative data for the two groups. There were no significant differences in the general characteristics of the two groups. The preoperative infusion times in the AAD and D groups were $14.7 \pm 4.9$ hours and $15.1 \pm 6.3$ hours, respectively.

The mean core temperatures began to decrease after the induction of anesthesia in both groups and continued to decrease during the course of surgery (Fig. 1). Although the mean core temperatures in the AAD group were higher than in the $\mathrm{D}$ group during the entire surgical period, there was no significant difference between the two groups except at the $45^{\text {th }}$ and 90th minutes of the operation (Table 3 ).

Table 2. General characteristics of two groups

\begin{tabular}{lccc}
\hline & AAD & D & $\boldsymbol{p}$ value \\
\hline Female & 6 & 4 & - \\
Age (day) & $9.8 \pm 9.1$ & $10.7 \pm 12.3$ & 0.185 \\
Weight (gram) & $3037 \pm 204$ & $2800 \pm 702$ & 0.319 \\
Hemoglobin (gr/dl) & $14.00 \pm 0.89$ & $14.27 \pm 2.7$ & 0.710 \\
Body Temperature $\left({ }^{\circ} \mathrm{C}\right)$ & $36.5 \pm 0.1$ & $36.4 \pm 0.2$ & 0.200 \\
AmbientTemperature $\left({ }^{\circ} \mathrm{C}\right)$ & $25.4 \pm 0.2$ & $25.3 \pm 0.3$ & 0.545 \\
Infusion Time (preop) $(\mathrm{h})$ & $14.7 \pm 4.9$ & $15.1 \pm 6.3$ & 0.877 \\
\hline
\end{tabular}

$\mathrm{AAD}=$ amino acid/dextrose group, $\mathrm{D}=$ dextrose group

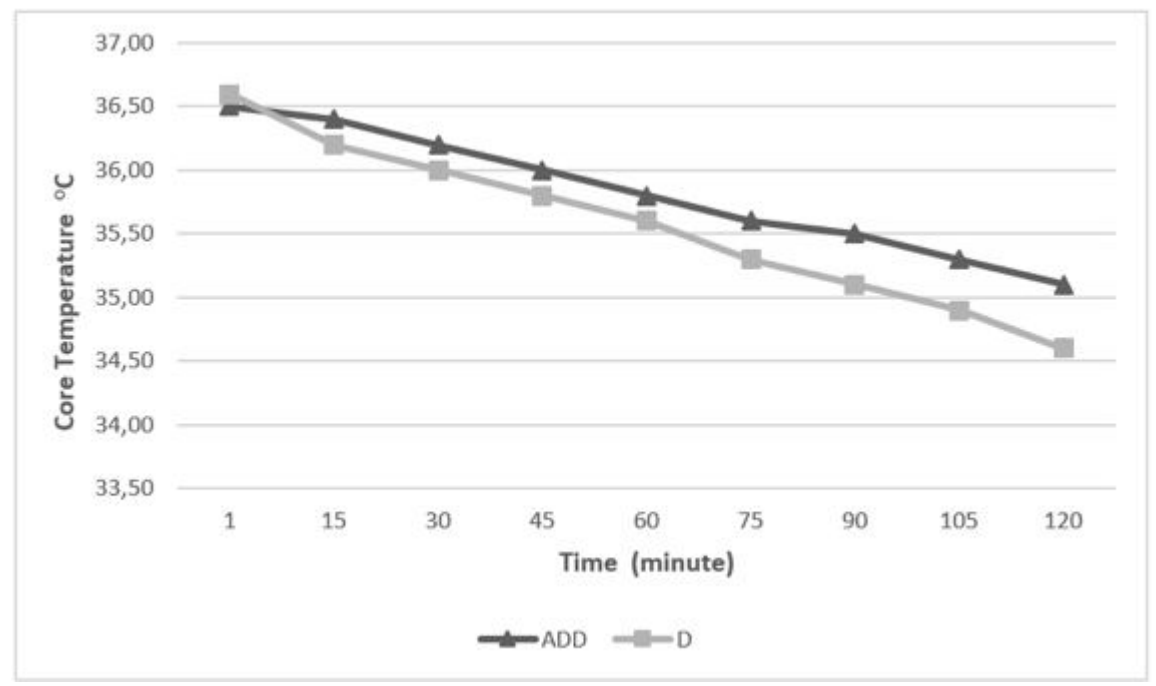

Fig. 1. Core body temperature changes in both groups. 
Table 3. Measured core temperatures and differences

\begin{tabular}{lccc}
\hline Time (min.) & AAD & D & $\boldsymbol{p}$ value \\
\hline 1. & $36.50 \pm 0.14$ & $36.60 \pm 0.13$ & 0.103 \\
15 & $36.4 \pm 0.19$ & $36.2 \pm 0.19$ & 0.083 \\
30 & $36.2 \pm 0.21$ & $36 \pm 0.18$ & 0.132 \\
45 & $36.0 \pm 0.2$ & $35.8 \pm 0.2$ & $\mathbf{0 . 0 1 8}^{*}$ \\
60 & $35.8 \pm 0.3$ & $35.6 \pm 0.2$ & 0.138 \\
75 & $35.6 \pm 0.4$ & $35.3 \pm 0.3$ & 0.180 \\
90 & $35.5 \pm 0.4$ & $35.1 \pm 0.2$ & $\mathbf{0 . 0 4 3}^{*}$ \\
105 & $35.3 \pm 0.5$ & $34.9 \pm 0.3$ & 0.128 \\
120 & $35.1 \pm 0.7$ & $34.6 \pm 0.2$ & 0.185 \\
\hline
\end{tabular}

$\mathrm{AAD}=$ amino acid/dextrose group, $\mathrm{D}=$ dextrose group, ${ }^{*} P<0.05$

\section{DISCUSSION}

General anesthesia impairs thermoregulation and causes mild hypothermia in surgical patients. Anesthesiologists and surgeons use various approaches and combinations to keep patients normothermic. Unfortunately, it has not yet been possible to solve the problem completely. However, there is one additional internal warming method that has been known since the 1990s: amino acid-induced thermoregulation. Amino acids infused in the body stimulate both protein synthesis and breakdown and also increase blood flow, especially in extrasplanchic tissue [15].

All reactions require larger amounts of energy compared with glucose or lipid metabolism, leading to accumulating heat in the body [11]. After Sellden et al. reported that amino acid infusion prevented perioperative hypothermia during anesthesia without any additional sympathoadrenal activity and shortened hospital stay [6, 15, 16], Kasai et al. [8] reported perioperative amino acids maintained core temperature and were useful in preventing hypothermia not only during general anesthesia but also during spinal anesthesia. A contribution to the subject also came from Nakajima et al. [10]; amino acid infusion increased both metabolic rates and resting core temperature, but they also produced a synchronous increase in all major autonomic thermoregulatory defense thresholds at the same time.

Non-shivering thermogenesis (activation of brown fat by an uncoupling protein, thermogenin) is used in preference to shivering in infants and in small mam- mals $[1,12,14]$. It is thought that because of their high amounts of brown adipose tissue and their high potential for non-shivering thermogenesis, newborns should be able to produce more heat to compensate for heat loss in general anesthesia, but this is not the case. Newborns, like adults, are unable to respond to intraoperative hypothermia because inhibition of non-shivering thermogenesis occurs during general anesthesia [17-19]. In these circumstances, it might be considered that perioperative infusion of amino acids would increase heat formation via potentiation of nonshivering thermogenesis. However, the results of the current study do not support this hypothesis. Although the mean temperature of the AAD group was higher during anesthesia, the difference was not statistically significant.

\section{Limitations}

First, the operating room temperature could only be adjusted to about $22-23^{\circ} \mathrm{C}$ instead of $25^{\circ} \mathrm{C}$, so a further decrease in body core temperature might have led to an increase in the thermogenic effect of amino acids. On the other hand, this could be more realistic because most of the time the operating room temperature was around $21-22^{\circ} \mathrm{C}$. Although the optimal delivery room temperature is recommended to be 25 $28^{\circ} \mathrm{C}$, it is also a fact that $25^{\circ} \mathrm{C}$ is an uncomfortable temperature for all operating room staff [20].

Second, we could have given an amino acid solution without dextrose during the surgery because glucose supplementation inhibits endogenous glucose production and stimulates insulin secretion to a greater 
extent than the administration of amino acids alone in adults. Moreover, intraoperative exogenous glucose suppresses protein catabolism and gluconeogenesis. Therefore, excessive glucose administration may disturb amino acid-mediated thermogenesis [21]. According to Fujita et al. [22], intraoperative amino acid infusion without glucose administration appears to be more effective for body temperature maintenance in patients undergoing colorectal surgery. However, we thought that it would be inappropriate to give amino acid solutions alone in newborns who are prone to hypoglycemia in long surgical procedures.

Third, there may be a linear relationship between the amount of amino acids and the thermogenic effect. Some groups given different amount of amino acids could be added.

In addition, cold ambient room temperature (below $23^{\circ} \mathrm{C}$ ) can significantly interfere with the maintenance of core temperature in newborns and infants during anesthesia. However, neonates cannot maintain their core temperature, even in warmer operating room temperatures [5]. Despite taking all necessary precautions, as mentioned previously, we observed mild hypothermia in both groups during surgery. Hypothermia developed in all newborns when surgical time exceeded one hour, even though the operating room temperature was around $25^{\circ} \mathrm{C}$.

\section{CONCLUSION}

Hypothermia develops in all neonates when surgical time exceeds one hour, even in warmer ambient temperature. Although it seems effective in adults, amino acid- induced thermoregulation does not seem effective in newborns during general anesthesia. This effect may be dose-dependent. Studies with more groups and different amino acid doses are needed.

\section{Acknowledgments}

All procedures performed in studies involving human participants were accordance with the ethical standards of the institutional and/or national research committee and with the 1964 Helsinki declaration and its later amendments or comparable ethical standards. Both authors were working in Istanbul University during the study.

\section{Authors' Contributions}

Conception and design: M.O, F.T.S; Data analysis interpretation: M.O, F.T.S; Manuscript writing and revision: M.O, F.T.S

\section{Conflict of interest}

The author disclosed no conflict of interest during the preparation or publication of this manuscript.

\section{Financing}

The authors disclosed that they did not receive any grant during conduction or writing of this study.

\section{REFERENCES}

1. Sessler DI. Perioperative thermoregulation and heat balance. Lancet 2016;387:2655-64.

2. Insler SR, Sessler DI. Perioperative thermoregulation and temperature monitoring. Anesthesiology Clin 2006;24:823-37.

3. Sessler DI. Complications and treatment of mild hypothermia. Anesthesiology 2001;95:531-43.

4. Kurz A, Sessler DI, Lenhardt R. Perioperative normothermia to reduce the incidence of surgical-wounds infection and shorten hospital stay. N Engl J Med 1996;334;1209-15.

5. Tander B, Barış S, Karakaya D, Arıtürk E, Rızalar R, Bernay B. Risk factors influencing inadvertent hypothermia in infants and neonates during anesthesia. Pediatr Anesth 2005;15:574-9. 6. Sellden E, Lindahl SGE. Amino acid-induced thermogenesis reduces hypothermia during anaesthesia and shortens hospital stay. Anesth Analg 1999; 89:916-22.

7. Sellden E. Peri-operative amino acid administration and the metabolic response to surgery. Proc Nutr Soc 2002;61:337-43. 8. Kasai T, Nakajima Y, Matsukawa T, Ueno H, Sanaguchi M, Mizobe T. Effect of preoperative amino acid infusion on thermoregulatory response during spinal anaesthesia. Br J Anaesth 2003;90:58-61.

9. Yamaoka I. Modification of core body temperature by amino acid administration. Asia Pac J ClinNutr 2008;17:309-11.

10. Nakajima Y, Takamata A, Matsukawa T, Sessler DI, Kitamura $\mathrm{Y}$, Ueno H, et al. Effect of amino acid infusion on central thermoregulatory control in humans. Anesthesiology 2004;100:634-39.

11. Yokoyama T, Yamaoka I, Hitosugi T, Sellden E. Amino acids during perioperative period. Open J Anesthesiol 2017;7:287-95.

12. Himms-Hagen J. Nonshivering thermogenesis. Brain Res Bull 1984;12:151-60.

13. Cypess AM, Lehman S, Williams G, Tal I, Rodman D, Goldfine AB, et al. Identification and importance of brown adipose tissue in adult humans. N Eng J Med 2009;360:1509-17. 14. Gunn TR, Gluckman PD. Perinatal thermogenesis. Early Hum Dev 1995;42:169-83.

15. Sellden E, Branström R, Brundin T. Augmented thermic 
effect of amino acids under general anaesthesia occurs mainly in extra-splanchnic tissues. Clin Sci 1996;91:431-9.

16. Sellden E, Lindahl SGE. Amino acid-induced thermogenesis to prevent hypothermia during anesthesia is not associated with increased stress response. Anesth Analg 1998:87;637-40.

17. Ohlson K, Lindahl S, Cannon B, Nedergaard J. Thermogenesis inhibition in brown adipocytes is a specific property in volatile anesthetics. Anesthesiology 2003;98:437-48.

18. Plattner O, Semsroth M, Sessler DI, Papousek A, Klasen C, Wagner O. Lack of nonshivering thermogenesis in infants anaesthetized with fentanyl and propofol. Anesthesiology 1997;86:772-7.

19. Dicker A, Ohlson KBE, Johnson L, Cannon B, Lindahl SGE,
Nedergaard J. Halothane selectively inhibits nonshivering thermogenesis. Anesthesiology 1995;82:491-501.

20. Sultan P, Habib AS, Carvalho B. Ambient operating room temperature: mother, baby or surgeon? $\mathrm{Br} \mathrm{J}$ Anaesth 2017; 119:839.

21. Schricker T, Meterissian S, Donatelli F, Carvalho G, Mazza L, Eberhart E, et al. Parenteral nutrition and protein sparing after surgery: do we need glucose? Metabolism 2007;56:1044-50.

22. Fujita Y, Tokunaga C, Yamaguchi S, Nakamura K, Horiguchi $\mathrm{Y}$, Kaneko M, et al. Effect of intraoperative amino acids with or without glucose infusion on body temperature, insulin, and blood glucose levels in patients undergoing laparoscopic colectomy: A preliminary report. Acta Anaesthesiol Taiwan 2014;52:101-6. 